\title{
Identifying Fenton-Reacted Trimethoprim Transformation Products Using Differential Mobility Spectrometry
}

\author{
Jarrod M. Psutka, ${ }^{1}$ Annick Dion-Fortier, ${ }^{2}$ Thorsten Dieckmann, ${ }^{1}$ J. Larry Campbell, ${ }^{1,3,{ }^{*}}$ Pedro A. Se- \\ gura,,$^{2,}$ W. Scott Hopkins ${ }^{1, *}$
}

\author{
1. Department of Chemistry, University of Waterloo, Waterloo, ON N2L 3G1 \\ 2. Department of Chemistry, Université de Sherbrooke, Sherbrooke, QC J1K 2R1 \\ 3. SCIEX, 71 Four Valley Drive, Concord, ON, L4K 4V8 Canada
}

\begin{abstract}
A transformation product of trimethoprim, a contaminant of emerging concern in the environment, is generated using an electro-assisted Fenton reaction and analyzed using differential mobility spectrometry (DMS) in combination with MS/MS techniques and computational calculations to develop a rapid method for identification. DMS is used as a pre-filter to separate positional isomers prior to subsequent identification by mass spectrometric analyses. Collision induced dissociation of each DMS separated species is used to reveal fragmentation patterns that can be correlated to specific isomer structures. Analysis of the experimental data and supporting quantum chemical calculations show that methylene-hydroxylated and methoxy-containing phenyl ring hydroxylated transformation products are observed. The proposed methodology outlines a high-throughput technique to determine transformation products of small molecules accurately, in a short time and requiring minimal sample concentrations $(<100 \mathrm{ng} / \mathrm{mL})$.
\end{abstract}

The presence of organic micropollutants such as pharmaceuticals, personal care products, and consumer product additives in aquatic environments has been extensively reported in the last 20 years. ${ }^{1-3}$ Studies have shown that the one of the major points of entry of these compounds into surface waters are municipal wastewater treatment plants. ${ }^{4}$ Since many of these compounds are biologically active, even at environmental concentrations $(<1 \mu \mathrm{g} / \mathrm{L})$, and the effects of mixtures of these compounds are not yet understood, their removal in wastewater plant secondary and tertiary treatments has been studied extensively. ${ }^{5-7}$ To date, advanced oxidation processes, based on the production of hydroxyl and other radicals to oxidize organic compounds, is one of the most promising tertiary treatments. ${ }^{8-10}$ However, it is known that in many cases advanced oxidation processes are not able to completely mineralize (i.e., transform into inorganic species such as $\mathrm{H}_{2} \mathrm{O}, \mathrm{CO}_{2}$, and $\mathrm{NH}_{3}$ ) the contaminants of interest, and transformation products that may have unknown behavior are commonly generated. ${ }^{11}$ For those reasons, a great deal of effort has been directed towards the determination of transformation products of organic micropollutants (TPOMs) generated after water treatment. Such studies are challenging since the low concentration of TPOMs and the complexity of environmental samples hinder the application of many of the techniques available to modern chemists such as infrared spectroscopy, x-ray diffraction and nuclear magnetic resonance. For that reason, the characterization of TPOMs has been predominantly mass spectrometry-based. To improve the certitude of the identification of TPOMs, a series of identification levels, based on the application of mass spectrometry techniques able to deliver increasingly detailed information on the structure of small molecules, have been recently proposed by Schymanski, et al. ${ }^{12}$ For example, level 5, the lowest level, is attained by performing accurate mass measurements. Level 2, probable structure, can only be reached when obtaining a library spectrum match or other diagnostic evidence. To reach level 1 a reference standard is needed. Elucidation of the structure of TPOMs is important since biological activity can be conserved or modified upon transformation. ${ }^{13}$ While high-resolution tandem mass spectrometry studies are useful for identifying accurate mass and proposing tentative structures, such approaches are limited when dealing with TPOMs that have been not been included in spectral libraries or when a diverse set of positional isomers are possible. Therefore, additional diagnostic techniques able to give detailed molecular structural information, such as the location of specific functional groups in small molecules, are needed to improve the identification accuracy of TPOM structures. Recently, ion mobility spectrometry (IMS) has been employed to detect organic molecules in an efficient manner. ${ }^{14,15}$ However, separating and classifying TPOM structures using only IMS proved difficult and modifications to the workflow must be made to improve accuracy and efficiency.

Differential mobility spectrometry (DMS) - a for of ion mobility commonly performed at atmospheric pressure - separates ions based on differences in their mobility under high- and lowfield conditions. A typical DMS experiment involves entraining ions of interest in a carrier gas, often $\mathrm{N}_{2}$, which transports the sample ions through the DMS cell. Two planar parallel electrodes are then used to apply an alternating asymmetric separation voltage (SV) transverse to the carrier gas flow. Owing to their differential mobilities under the high-field and low-field portions of the asymmetric waveform, the ions migrate off the axis defined by the gas flow and towards one of the electrodes. A DC compensation voltage (CV) may then applied to correct the ion trajectory such that ions are transmitted to the detector, in this case a mass spectrometer. ${ }^{16,17}$ Thus, an ion's differential mobility is encoded into the CV required for optimal transmission through the DMS cell. To date, DMS has been used to separate and detect a wide range of chemical species (including isomers, ${ }^{18}$ conformers, ${ }^{19}$ and tautomers ${ }^{20}$ ). Oftentimes, these separations are facilitated by the introduction of chemical modifiers (viz. solvent vapor) to the DMS collision gas, which results in dynamic, field-dependent growth and evaporation of ion-solvent clusters. ${ }^{16}$

Recently, it has been shown that DMS can be used as an alternative to traditional LCMS/MS techniques for separating species in complex samples. ${ }^{21-23}$ For example, Porta et al. used DMS instead of LC to modify their liquid surface extraction analysis of many drugs from human kidney and tissue cross 
sections, and reported a 3-6 fold improvement in analysis time. ${ }^{24} \mathrm{DMS} / \mathrm{MS}$ techniques have also been employed as a rapid characterization method for small organic molecules in ground water. For example, Noestheden et al. successfully separated and characterized naphthenic acid derivatives from ground water affected by oil sands processing. ${ }^{25}$ Here, we demonstrate the potential of DMS to be used as a diagnostic technique for the structural identification of TPOMs. We focus on the transformation products of trimethoprim, a widely reported antibiotic in environmental waters, ${ }^{26-28}$ specifically the hydroxylated forms of trimethoprim. These TPOMs, known that the oxidation of organic compounds in the electro-assisted Fenton reaction is due to the production of highly reactive $\mathrm{OH} \bullet$ radicals. Therefore it was hypothesized that TP306 is the result of $\mathrm{H}$ abstraction or addition reactions initiated by $\mathrm{OH} \bullet$ that yield hydroxylated products. ${ }^{33,34}$

\section{EXPERIMENTAL \& COMPUTATIONAL METHODS}

Reagents and Chemicals. Trimethoprim was purchased from Santa-Cruz Biotechnology, and iron (II) sulfate $\left(\mathrm{FeSO}_{4}\right)$ and sodium sulfate $\left(\mathrm{Na}_{2} \mathrm{SO}_{4}\right)$ were obtained from Sigma-Aldrich, all with a purity $\geq 98 \%$. Sulfuric acid $\left(\mathrm{H}_{2} \mathrm{SO}_{4}\right)$ and sodium hydroxide $0.1 \mathrm{M}$ were obtained from Fisher Scientific. Solvents and additives used in liquid chromatography-mass spectrometry or solid-phase extraction experiments, such as acetonitrile (Optima LC/MS grade), methanol (Optima LC/MS grade), water (Optima LC/MS grade), formic acid (Optima LC/MS grade) and ethylenediaminetetraacetic acid disodium salt ( $\mathrm{Na}_{2}$ EDTA, ACS grade) were purchased from Fisher Scientific.

Preparation and Purification of Transformation Product TP306. Electro-assisted Fenton reaction experiments were carried out with a potentiostat/galvanostat EG\&G model 273A from Princeton Applied Research in the galvanostatic mode in a cell with one compartment and two electrodes. ${ }^{29-31}$ The counter/reference electrode was made of $\mathrm{Pt}$ and the working electrode was made of glassy carbon. A bubble generator was inserted in the cell to create agitation during the reaction. The solution contained $50 \mathrm{mM}$ of $\mathrm{Na}_{2} \mathrm{SO}_{4}$ as electrolyte, $0.1 \mathrm{mM}$ of $\mathrm{FeSO}_{4}$ as iron source for the Fenton reaction and $0.2 \mathrm{mM}$ of trimethoprim. The $\mathrm{pH}$ of the solution was adjusted to $\mathrm{pH} 2.7$ with $\mathrm{H}_{2} \mathrm{SO}_{4}$. The current was adjusted to $1 \mathrm{~mA}$ and the reaction time was $60 \mathrm{~min}$. At the end of the reaction, the solution was transferred to an amber vial.

Preliminary analyses by liquid chromatography-quadrupoletime-of-flight mass spectrometry (LC-QqTOFMS) of the trimethoprim solution oxidized by the electro-assisted Fenton reaction showed the presence of a major peak corresponding to a compound, or an unresolved mixture of compounds, with $\mathrm{m} / \mathrm{z}$ 307.1412. This species, which is referred to as TP306 owing to its neutral mass of $306 \mathrm{Da}$, eluted at $2.3 \mathrm{~min}$. Another compound of $\mathrm{m} / \mathrm{z} 306.8527$, which eluted at $0.3 \mathrm{~min}$, was also observed in preliminary DMS-MS experiments (see Supporting Information for details). Since both the $\mathrm{m} / \mathrm{z} 307.1412$ and $\mathrm{m} / \mathrm{z}$ 306.8527 species were simultaneously transmitted by the first quadrupole mass filter, a cleanup procedure based on solidphase extraction (SPE) was used to remove the $m / z 306.8527$ interference for preliminary experiments. The sample was adjusted to pH 9 using $0.1 \mathrm{M} \mathrm{NaOH}$, and $\mathrm{Na}_{2}$ EDTA at a concentration of $200 \mathrm{mg} / \mathrm{L}$ was added to complex residual iron on the solution. Then the sample was introduced in Strata-X polymeric reversed phase SPE cartridges $(200 \mathrm{mg}, 6 \mathrm{~mL}, 33 \mu \mathrm{m})$ from Phenomenex previously conditioned with $5 \mathrm{~mL} \mathrm{ACN/MeOH}$
1:1 followed by $\mathrm{H}_{2} \mathrm{O}$ at $\mathrm{pH}$ 9. The cartridge was subsequently rinsed with $2 \times 5 \mathrm{~mL}$ of $\mathrm{H}_{2} \mathrm{O}$ to remove the hydrophilic impurity and TP306 was eluted from the cartridge using $2 \times 2.5 \mathrm{~mL}$ of $\mathrm{ACN} / \mathrm{MeOH} 1: 1$. Analysis of the cleaned sample did not show the presence of the interfering compound. Note that following characterization of the $\mathrm{m} / \mathrm{z} 307.1412$ species (vide infra), it was no longer necessary to conduct the SPE cleanup procedure since the $\mathrm{m} / \mathrm{z} 307.1412$ species could be identified via diagnostic multiple reaction monitoring (MRM) transitions.

Differential Mobility Spectrometry - Mass Spectrometry. Experiments were carried out using a DMS mated to a hybrid quadrupole linear ion trap mass spectrometer (SCIEX). A schematic diagram of the instrument is provided in the supporting information which accompanies this manuscript. Positive mode ESI conditions were used with an electrospray voltage of 5.5 $\mathrm{kV}$, nebulizing gas pressure of $20 \mathrm{psi}$, and ambient source temperature $\left(\sim 33^{\circ} \mathrm{C}\right)$. The temperature in the DMS was set to 150 ${ }^{\circ} \mathrm{C}$ and $\mathrm{N}_{2}$ curtain gas pressure was set at 20 psi. The separation voltages (SV) were stepped from $\mathrm{SV}=0-4000 \mathrm{~V}$ in $500-\mathrm{V}$ increments. At each SV, the compensation voltage $(\mathrm{CV})$ was ramped from $-50 \mathrm{~V}$ to $+20 \mathrm{~V}$ in $0.1-\mathrm{V}$ step increments. The resulting series of ionograms were used to generate dispersion plots that indicate how the observed ions behave in the dynamic DMS environment. ${ }^{32}$ To vary the collision/clustering environment of the DMS cell, $1.5 \%$ (mole ratio) methanol or isopropyl alcohol (Sigma-Aldrich) were introduced into the curtain gas. Solutions containing TP306 were diluted to a concentration of $22 \mathrm{ng} / \mathrm{mL}$ in a $1: 1$ solution of milli-Q water and methanol with $0.1 \%$ formic acid to aid protonation of the analytes. Collisioninduced dissociation (CID or MS/MS) experiments involved the use of $\sim 9$ mTorr of nitrogen as a collision gas to induce fragmentation. These CID experiments were performed at set SV and $\mathrm{CV}$ values to select specific isomer species (vide infra), and collision energy was ramped from $+5 \mathrm{~V}$ to $+120 \mathrm{~V}$ with an increment of $0.25 \mathrm{~V}$.

Computational Methods. It is known that the oxidation of organic compounds in the electro-assisted Fenton reaction is due to the production of highly reactive $\mathrm{OH} \bullet$ radicals. Therefore it was hypothesized that TP306 is the result of $\mathrm{H}$ abstraction or addition reactions initiated by $\mathrm{OH} \cdot$ that yield hydroxylated products. ${ }^{33,34}$ To study the proposed hydroxylated products of trimethoprim (TP306) computationally, all possible hydroxylation sites of neutral trimethoprim were manually generated and all possible protonated forms of these species were optimized with density functional theory (DFT) at the B3LYP level of theory using a $6-311 \mathrm{G}++(\mathrm{d}, \mathrm{p})$ basis set as implemented in the Gaussian 16 software package. ${ }^{35}$ Following geometry optimization, harmonic frequencies were calculated to estimate thermochemical corrections and ensure that each structure was a local minimum (i.e., isomer) on the potential energy surface. The lowest energy protonated structures were also optimized in the presence of an isopropyl alcohol molecule to explore the possibility of solvent induced tautomerization. ${ }^{20,36}$ The resulting structures were sorted based on their standard Gibbs' energies to determine the structures that are likely to exist in the DMS cell. All computational results are provided in the supporting information.

\section{RESULTS AND DISCUSSION}

Figures 1A-C show the dispersion plots acquired for protonated TP306, ( $m / z$ 307.1), in pure $\mathrm{N}_{2}, \mathrm{~N}_{2}$ seeded with methanol $(\mathrm{MeOH})$, and $\mathrm{N}_{2}$ seeded with isopropyl alcohol (IPA), 
respectively. Although different isomeric species could not be separated in the pure $\mathrm{N}_{2}$ environment, upon introducing $\mathrm{MeOH}$ or IPA modifier, signals corresponding to multiple ion-types were observed. Figure 1D shows the ionogram recorded at $\mathrm{SV}=$ $3500 \mathrm{~V}$ for TP306 in the $\mathrm{N}_{2}$ environment seeded with IPA vapor. In principle, the observation of three well-resolved peaks in an ionogram could be indicative of the presence of at least three isomeric structures. However, caution must be taken when assigning peaks following separation by an IPA environment because protic solvent vapor has been shown to drive tautomerization and skew relative isomer populations. ${ }^{20,36}$ It is also possible that the TP306 signal is produced via fragmentation of a larger, TP306-containing cluster. In addition, one or more of these peaks could correspond to an isobaric interference (i.e., an ion of the same nominal $\mathrm{m} / \mathrm{z}$ value as the target analyte, but different molecular formula). Consequently, further characterization of the ions associated with each ionogram peak is necessary.

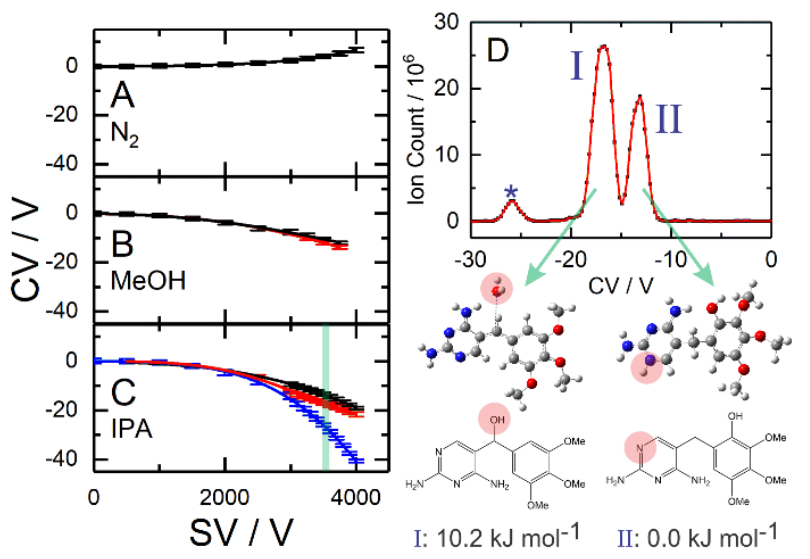

Figure 1. Dispersion plots recorded for $(\mathrm{TP} 306+\mathrm{H})^{+}$in (A) a pure $\mathrm{N}_{2}$ environment, and $\mathrm{N}_{2}$ seeded with $1.5 \%(\mathrm{v} / \mathrm{v})(\mathrm{B})$ methanol vapor and (C) isopropanol vapor. (D) The ionogram observed at $\mathrm{SV}=3500 \mathrm{~V}$ in the IPA-modified environment (highlighted in green in $1 \mathrm{C}$ ). Inset: the two lowest energy isomers of $(\mathrm{TP} 306+\mathrm{H})^{+}$as calculated at the B3LYP/6-311G $++(\mathrm{d}, \mathrm{p})$ level of theory. Standard Gibbs' energies are reported.

To determine whether the observed ion signals were from TP306 and not from fragmentation of larger clusters, the declustering potential (DP) at the input of the mass spectrometer was ramped and in-source fragmentation was monitored. ${ }^{20,37}$ Figure 2 shows the behavior of the separated ion signals at $\mathrm{SV}=3500$ $\mathrm{V}$ as a function of DP voltage. The two most intense features in the ionogram depleted with increasing DP, indicating fragmentation of bare ions of $(\mathrm{TP} 306+\mathrm{H})^{+}$. In contrast, the intensity of the weakest feature (indicated with an asterisk in Figure 1D) remained constant over the range of DP values, suggesting that in-source fragmentation is balanced by production of $\mathrm{m} / \mathrm{z} 307.1$ from dissociation of larger clusters. This is further supported by collision-induced dissociation (CID) of the species transmitted at $\mathrm{CV}=-26 \mathrm{~V}$, which yields successive loses of $60 \mathrm{Da}$ even at very low collision energies, thus suggesting that this feature is associated with an ion-solvent cluster (see supporting information for details).

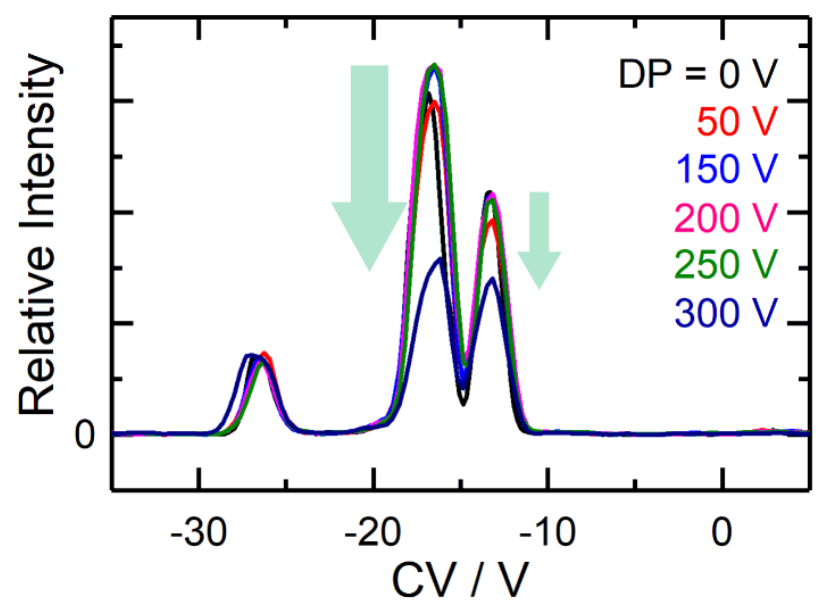

Figure 2. The ionogram observed at $\mathrm{SV}=3500 \mathrm{~V}$ in the IPAmodified environment as a function of declustering potential (DP). The ion signals at $\mathrm{CV}=-13 \mathrm{~V}$ and $-16 \mathrm{~V}$ deplete with increasing DP voltage due to in-source CID, thus indicating that these peaks are associated with $(\mathrm{TP} 306+\mathrm{H})^{+}$and not other noncovalent adduct forms. ${ }^{20,37}$

The assignment of molecular structures to the ions selected at $\mathrm{CV}=-16 \mathrm{~V}$ and $\mathrm{CV}=-13 \mathrm{~V}$ (peaks I and II in Figure 1D) was guided by our computational study. In total, 38 different stable isomers of $(\mathrm{TP} 306+\mathrm{H})^{+}$were identified in our search. The two lowest energy isomers are shown in Figure 1. Note that the second lowest energy isomer (assigned to peak I) optimized to a carbocation/water association complex at the B3LYP/6$311 \mathrm{G}++(\mathrm{d}, \mathrm{p})$ level of theory. This is not unexpected since protonation of alcohols commonly results in loss of water, and often yields the $\left(\mathrm{M}-\mathrm{H}_{2} \mathrm{O}\right)^{+}$fragment peak as the base peak in the mass spectrum, ${ }^{38,39}$ although this is not the case in experimental spectra recorded for $(\mathrm{TP} 306+\mathrm{H})^{+}$. The assignment of peak I to the second lowest energy isomer is supported by the observed fragmentation spectrum following CID (shown in Figure 3A), where the major fragmentation product corresponds to water loss from (TP306 $+\mathrm{H})^{+}$. By monitoring the observed fragmentation products as a function of collision energy $(\mathrm{CE})$, one is able to record breakdown curves for the ion of interest. ${ }^{20,40}$ The breakdown curve for the second lowest energy isomer of $(\mathrm{TP} 306+\mathrm{H})^{+}$is shown in Figure 3C. Three major product channels are observed for isomer 2 (Peak I). Assignment of the fragmentation pathways and products is provided in Scheme I. Note that channel $\mathrm{Ib}$ is associated with demethylation of the exposed methyl ether groups bound to the resonance stabilized aromatic system, as observed in previous CID studies of trimethoprim. ${ }^{41}$ 


$$
\underset{\left[\mathrm{C}_{12} \mathrm{H}_{11} \mathrm{~N}_{4} \mathrm{O}_{3}\right]^{+}}{m / \mathrm{z} 259_{\left(\mathrm{minor}_{2}\right.}}
$$

Scheme 1. The fragmentation channels observed via ionogram Peak I (see Figure 1), attributed to isomer 2. The site of protonation is highlighted in red.

The fragmentation spectrum and breakdown curve for the global minimum isomer of $(\mathrm{TP} 306+\mathrm{H})^{+}$are shown in Figures $3 \mathrm{~B}$ and $3 \mathrm{D}$, respectively. It is immediately obvious that the global minimum structure and isomer 2 have very different fragmentation patterns. Four major product channels are observed for the global minimum structure (Peak II). Assignment of the fragmentation pathways and products of the global minimum structure is provided in Scheme II. Channels IIa and IIb are associated with successive demethylation of the methyl ether groups (as described above). Channel IIc is associated with water loss from the cationic fragment remaining following the loss of the second $\mathrm{CH}_{3}$ group, and channel IId is associated with cleavage of the methylene linkage between the two aromatic ring systems. The fact that water loss is a relatively high energy process in this case, and that the charge remains on the nitrogen-bearing fragment following cleavage at the bridging methylene group, both support the assignment of peak II to the calculated global minimum structure.<smiles></smiles>

$$
\begin{aligned}
& {\left[\mathrm{C}_{14} \mathrm{H}_{19} \mathrm{~N}_{4} \mathrm{O}_{4}\right]^{+}} \\
& -\mathrm{H}_{3} \mathrm{C} \downarrow^{m / z 307}-\mathrm{C}_{9} \mathrm{H}_{11} \mathrm{O}_{4} \\
& {\left[\mathrm{C}_{13} \mathrm{H}_{16} \mathrm{~N}_{4} \mathrm{O}_{4}\right]^{+} \quad\left[\mathrm{C}_{5} \mathrm{H}_{7} \mathrm{~N}_{4}\right]^{+}} \\
& \mathrm{m} / \mathrm{z} 292 \text { - IIa } \mathrm{m} / \mathrm{z} 123 \nabla \mathrm{IId} \\
& \downarrow-\mathrm{H}_{3} \mathrm{C} \\
& {\left[\mathrm{C}_{14} \mathrm{H}_{17} \mathrm{~N}_{4} \mathrm{O}_{3}\right]^{+}} \\
& \mathrm{m} / \mathrm{z} 277 \\
& \Delta \mathrm{IIb} \\
& \downarrow-\mathrm{H}_{2} \mathrm{O} \\
& {\left[\mathrm{C}_{14} \mathrm{H}_{17} \mathrm{~N}_{4} \mathrm{O}_{3}\right]^{+}} \\
& \mathrm{m} / \mathrm{z} 259 \\
& \text { IIC }
\end{aligned}
$$

Scheme 2. The fragmentation channels observed via ionogram Peak II (see Figure 1), attributed to isomer 1 (i.e., global minimum). The site of protonation is highlighted in red.

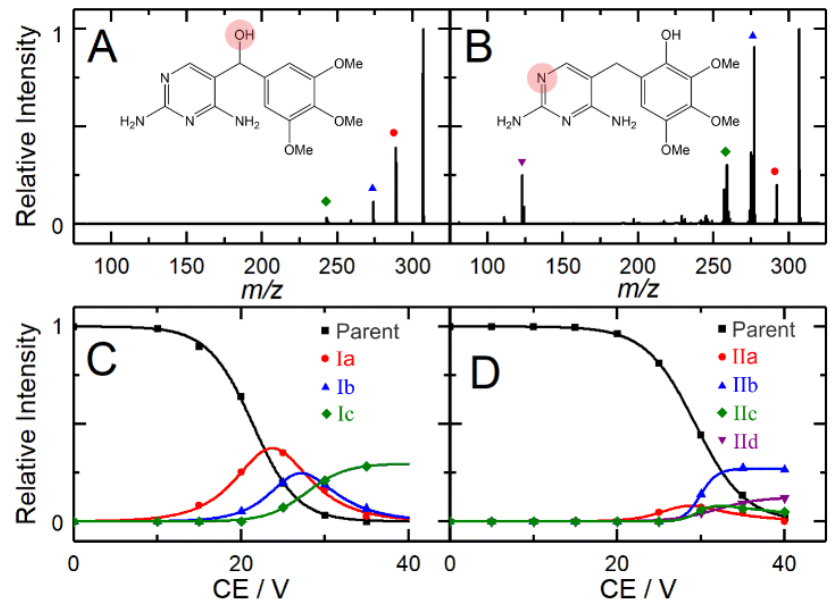

Figure 3. (A) Fragmentation spectrum observed for isomer 2 (peak I) following CID at $\mathrm{CE}=20 \mathrm{eV}$ (est. lab frame). (B) Fragmentation spectrum observed for isomer 1 (peak II) following $\mathrm{CID}$ at $\mathrm{CE}=35 \mathrm{eV}$ (est. lab frame). Breakdown curves for (C) isomer 2 and (D) isomer 1. Product channels are described in the text and shown in Schemes I and II.

\section{CONCLUSION}

The electro-assisted Fenton reaction was used to generate transformation products of trimethoprim, an antibiotic which is commonly found in environmental waters. Two major isomeric transformation products with masses 16 Da higher than trimethoprim were separated and isolated with differential mobility spectrometry prior to mass spectrometric analysis. DMS separation of these hydroxylated species was enabled by seeding the $\mathrm{N}_{2}$ collision gas in the DMS cell with a low vapor pressure of 
isopropanol. Subsequent characterization of the two isomers of $(\mathrm{TP} 306+\mathrm{H})^{+}$via CID showed that each isomer has a distinct fragmentation pattern, thus providing a prescription for unique identification via multiple reaction monitoring. Analysis of the fragmentation patterns and supporting quantum chemical calculations were used to determine the structures of the transformation products. Upon treatment with the Fenton reaction, trimethoprim becomes hydroxylated on the bridging methylene group or on the methoxy-containing phenyl ring. Assuming similar ionization efficiencies, these two positional isomers are produced with relative populations of $64 \%$ and $46 \%$, respectively. It is noteworthy that the electro-assisted Fenton treatment of trimethoprim did not yield any N-oxide isomers, which were proposed as possible products following in vitro treatment by pig liver microsomes. ${ }^{42}$

This study demonstrates a promising methodology for identifying transformation products of small organic molecules. The relatively low solution concentrations required by, and relatively fast analysis times of, DMS-MS/MS are attractive from a high-throughput standpoint, and outcomes are complementary to other techniques commonly used for compound identification (e.g., high resolution mass spectrometry and nuclear magnetic resonance). Furthermore, the specificity gained by DMS analysis can facilitate a reduction in the complexity of sample preparation, thus decreasing LC run times,${ }^{43}$ or enabling the replacement of the traditional and more resource intensive LC workflow. ${ }^{44}$ Moreover, given the capacity of the present technique to separate positional isomers, DMS-MS/MS expands the toolbox of environmental analysts to improve the identification of organic contaminants to higher levels of confidence.

\section{ASSOCIATED CONTENT}

\section{Supporting Information}

The Supporting Information is available free of charge on the ACS Publications website. The supporting information contains details on the contaminating species including breakdown curves and fragmentation spectra, information regarding the DMS instrument, isomeric labelling schemes, energetic ordering of possible isomers, calculated thermochemistry data of the studies isomers, LC/MS traces of the transformed trimethoprim sample, and XYZ coordinates of each geometrically optimized isomer are included.

\section{AUTHOR INFORMATION}

\section{Corresponding Author}

* Scott Hopkins: scott.hopkins@uwaterloo.ca; Pedro Segura: pedro.alejandro.segura@usherbrooke.ca; J. Larry Campbell: larry.campbell@sciex.com

\section{ACKNOWLEDGMENT}

The authors thank the Natural Sciences and Engineering Research Council (NSERC) and Ontario Centres of Excellence (OCE) for providing financial support necessary for this project. We additionally want to acknowledge Compute Canada for providing SHARCNET and allowing high performance computing for calculations in this research.

\section{REFERENCES}

(1) Monteiro, S.; Boxall, A. B. A. Rev. Environ. Contam. Toxicol. 2010, 202, 53-154.

(2) Hughes, S. R.; Kay, P.; Brown, L. E. Environ. Sci. Technol. 2013, 47 (2), 661-677.
Bradley, P. M.; Journey, C. A.; Romanok, K. M.; Barber, L. B.; Buxton, H. T.; Foreman, W. T.; Furlong, E. T.; Glassmeyer, S. T.; Hladik, M. L.; Iwanowicz, L. R.; Jones, D. K.; Kolpin, D. W.; Kuivila, K. M.; Loftin, K. A.; Mills, M. A.; Meyer, M. T.; Orlando, J. L.; Reilly, T. J.; Smalling, K. L.; Villeneuve, D. L. Environ. Sci. Technol. 2017, 51 (9), 4792-4802.

(4) Segura, P. A.; François, M.; Gagnon, C.; Sauvé, S. Environ. Health Perspect. 2009, 117 (5), 675-684.

(5) Brausch, J. M.; Connors, K. A.; Brooks, B. W.; Rand, G. M. Rev. Environ. Contam. Toxicol. 2012, 218, 1-99.

(6) Boxall, A. B. A.; Rudd, M. A.; Brooks, B. W.; Caldwell, D. J.; Choi, K.; Hickmann, S.; Innes, E.; Ostapyk, K.; Staveley, J. P.; Verslycke, T.; Ankley, G. T.; Beazley, K. F.; Belanger, S. E.; Berninger, J. P.; Carriquiriborde, P.; Coors, A.; DeLeo, P. C.; Dyer, S. D.; Ericson, J. F.; Gagné, F.; Giesy, J. P.; Gouin, T.; Hallstrom, L.; Karlsson, M. V; Larsson, D. G. J.; Lazorchak, J. M.; Mastrocco, F.; McLaughlin, A.; McMaster, M. E.; Meyerhoff, R. D.; Moore, R.; Parrott, J. L.; Snape, J. R.; MurraySmith, R.; Servos, M. R.; Sibley, P. K.; Straub, J. O.; Szabo, N. D.; Topp, E.; Tetreault, G. R.; Trudeau, V. L.; Van Der Kraak, G. Environ. Heal. Perspect. 2012, 120 (9), 1221-1229.

(7) Vasquez, M. I.; Lambrianides, A.; Schneider, M.; Kümmerer, K.; Fatta-Kassinos, D. J. Hazard. Mater. 2014, 279, 169-189.

(8) Suárez, S.; Carballa, M.; Omil, F.; Lema, J. M. Rev. Environ. Sci. Biotechnol. 2008, 7 (2), 125-138.

(9) Luo, Y.; Guo, W.; Ngo, H. H.; Nghiem, L. D.; Hai, F. I.; Zhang, J.; Liang, S.; Wang, X. C. Sci. Total Environ. 2014, 473-474, 619-641.

(10) Klavarioti, M.; Mantzavinos, D.; Kassinos, D. Environ. Int. 2009 35 (2), 402-417.

(11) Fatta-Kassinos, D.; Vasquez, M. I.; Kümmerer, K. Chemosphere 2011, 85 (5), 693-709.

(12) Schymanski, E. L.; Jeon, J.; Gulde, R.; Fenner, K.; Ruff, M.; Singer, H. P.; Hollender, J. Environ. Sci. Technol. 2014, 48 (4) 2097-2098.

(13) Boxall, A. B. A.; Sinclair, C. J.; Fenner, K.; Kolpin, D.; Maund S. J. Environ. Sci. Technol. 2004, 38 (19), 368A-375A.

(14) Wu, C.; Siems, W. F.; Asbury, G. R.; Hill, H. H. Anal. Chem. 1998, 70 (23), 4929-4938.

(15) Li, S.; Jia, J.; Gao, X.; He, X.; Li, J. Anal. Chim. Acta 2012, 720 97-103.

(16) Campbell, J.L., Le Blanc, J.C.Y. Bioanalysis 2015, 7 (7), 853 856.

(17) Sinatra, F. L.; Wu, T.; Manolakos, S.; Wang, J.; Evans-Nguyen, T. G. Anal. Chem. 2015, 87 (3), 1685-1693.

(18) Campbell, J. L.; Baba, T.; Liu, C.; Lane, C. S.; Le Blanc, J. C. Y.; Hager, J. W. J. Am. Soc. Mass Spectrom. 2017, 28 (7), 13741381.

(19) Shvartsburg, A. A.; Smith, R. D. Anal. Chem. 2013, 85 (14), 6967-6973.

(20) Anwar, A.; Psutka, J.; Walker, S. W. C.; Dieckmann, T.; Janizewski, J. S.; Campbell, J.L.; Hopkins, W.S. Int. J. Mass Spectrom. 2017.

(21) Schneider, B. B.; Covey, T. R.; Coy, S. L.; Krylov, E. V; Nazarov, E. G. Int. J. Mass Spectrom. 2011, 298, 45-54.

Davis, C. E.; Bogan, M. J.; Sankaran, S.; Molina, M. A.; Loyola, B. R.; Zhao, W.; Benner, W. H.; Schivo, M.; Farquar, G. R.; Kenyon, N. J.; Frank, M. IEEE Sens. J. 2010, 10 (1), 114-122.

(23) Eiceman, G. A.; Krylov, E. V.; Tadjikov, B.; Ewing, R. G.; Nazarov, E. G.; Miller, R. A. Analyst 2004, 129 (4), 297-304. Porta, T.; Varesio, E.; Hopfgartner, G. Anal. Chem. 2013, 85 (24), 11771-11779.

Noestheden, M. R.; Headley, J. V.; Peru, K. M.; Barrow, M. P.; Burton, L. L.; Sakuma, T.; Winkler, P.; Campbell, J. L. Environ. Sci. Technol. 2014, 48 (17), 10264-10272.

(26) Jewell, K. S.; Castronovo, S.; Wick, A.; Falås, P.; Joss, A.; Ternes, T. A. Water Res. 2016, 88, 550-557.

(27) Managaki, S.; Murata, A.; Takada, H.; Bui, C. T.; Chiem, N. H. Environ. Sci. Technol. 2007, 41 (23), 8004-8010.

(28) Chang, H.; Hu, J.; Asami, M.; Kunikane, S. J. Chromatogr. A 2008, $1190(1-2), 390-393$

(29) Jurva, U.; Wikström, H. V.; Bruins, A. P. Rapid Commun. Mass Spectrom. 2002, 16 (20), 1934-1940.

(30) Subramanyam, R.; Mishra, I. J. Hazardous, Toxic. 2012, 19, 218 229. 
(31) Segura, P. A. Environments 2018

(32) Campbell, J. L.; Zhu, M.; Hopkins, W. S. J. Am. Soc. Mass Spectrom. 2014, 25 (9), 1583-1591.

(33) Katoh, M.; Kurata, T.; Watanabe, Y.; Sawaki, Y. J. Am. Chem. Soc. 1988, 110 (22), 7472-7478.

(34) Thomas, C.; Mackey, M. M.; Diaz, A. A.; Cox, D. P. Redox Rep. 2009, 14 (3), 102-108.

(35) Becke, A. D. J. Chem. Phys. 1993, 98 (7), 5648.

(36) Campbell, J. L.; Yang, A. M. C.; Melo, L. R.; Hopkins, W. S. J. Am. Soc. Mass Spectrom. 2016, 27 (7), 1277-1284.

(37) Campbell, M. T.; Glish, G. L. Int. J. Mass Spectrom. 2018.

(38) Schwarz, H.; Stahl, D. Int. J. Mass Spectrom. Ion Phys. 1980, 36, 285-289.

(39) Wilfried, M. A. N.; Ricardo, A.; Correa, C. Interpretation of MS-
MS Mass Spectra of Drugs and Pesticides; 2017.

(40) Ramanathan, R.; Cao, K.; Cavalieri, E.; Gross, M. L. J. Am. Soc Mass Spectrom. 1998, 9 (6), 612-619.

(41) Eckers, C.; Monaghan, J. J.; Wolff, J.-C. Eur. J. Mass Spectrom. (Chichester, Eng). 2005, 11 (1), 73-82.

(42) Liu, Z. Y.; Wu, Y.; Sun, Z. L.; Wan, L. Biomed. Chromatogr. 2012, 26 (9), 1101-1108.

(43) Ray, J. A.; Kushnir, M. M.; Yost, R. A.; Rockwood, A. L.; Wayne Meikle, A. Clin. Chim. Acta 2014, 438, 330-336.

(44) Liu, C.; Gómez-Ríos, G. A.; Schneider, B. B.; Le Blanc, J. C. Y.; Reyes-Garcés, N.; Arnold, D. W.; Covey, T. R.; Pawliszyn, J. Anal. Chim. Acta 2017, 991, 89-94.

\section{Insert Table of Contents artwork here}

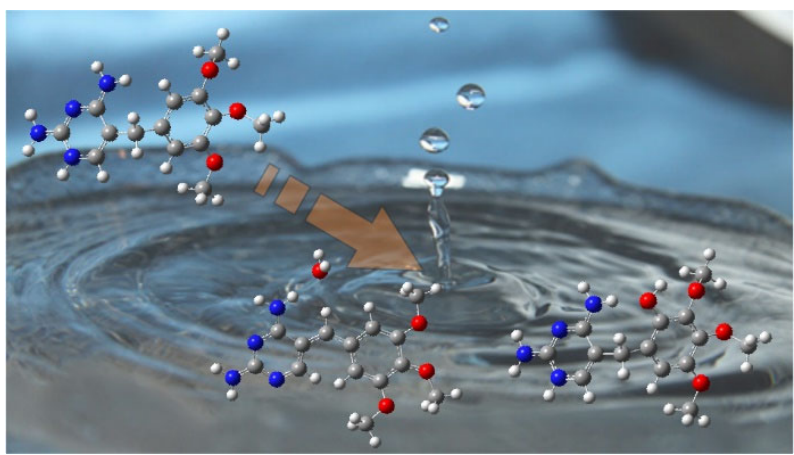

